\title{
There is no substitute for experience: Lessons learned from CHEST-1 (Chronic Thromboembolic Pulmonary Hypertension Soluble Guanylate Cyclase Stimulator Trial-1) for future clinical trial design
}

\author{
Jonathan D'Cunha, MD, PhD
}

\author{
From the Department of Cardiothoracic Surgery, University of Pittsburgh Medical Center, Pittsburgh, Pa. \\ Disclosures: Author has nothing to disclose with regard to commercial support. \\ Received for publication May 17, 2016; accepted for publication May 26, 2016; available ahead of print June 16, \\ 2016. \\ Address for reprints: Jonathan D'Cunha, MD, PhD, Department of Cardiothoracic Surgery, University of \\ Pittsburgh Medical Center, UPMC Presbyterian Suite C-900, 200 Lothrop St, Pittsburgh, PA 15213 (E-mail: \\ dcunhaj@upmc.edu). \\ J Thorac Cardiovasc Surg 2016;152:675-6 \\ $0022-5223 / \$ 36.00$ \\ Copyright () 2016 by The American Association for Thoracic Surgery \\ http://dx.doi.org/10.1016/j.jtcvs.2016.05.040
}

Chronic thromboembolic pulmonary hypertension (CTEPH) is an obstructive process of the pulmonary vasculature by residual organized thrombi that leads to increased pulmonary vascular resistance, progressive pulmonary hypertension $(\mathrm{PH})$, and eventual right ventricular failure. ${ }^{1-5}$ Prognosis is poor, and early diagnosis key to outcomes. Pulmonary endarterectomy (PEA) is the gold standard for treatment of chronic thromboembolic pulmonary hypertension. ${ }^{6}$ In some patients, PEA is potentially curative and the key is identification of those patients who will benefit from intervention.

Medical therapy is reserved for those patients with inoperable disease. Those patients with distal disease or persistent/recurrent $\mathrm{PH}$ after PEA should undergo medical treatment. Thus, appropriate assessment of operability is critical to success. The assessment of patients who would benefit from operability is subjective and challenging and poses a significant problem for risk assessment, clinical practice, and clinical trials for those patients with CTEPH.

In this issue of the Journal, Jenkins and colleagues ${ }^{7}$ present an expert opinion article in which they evaluate the operability assessment of patients in the CHEST-1 (Chronic Thromboembolic Pulmonary Hypertension Soluble Guanylate Cyclase Stimulator Trial-1) study. This work is interesting and timely in that it has broader implications for methodology as it relates to clinical trial design and execution. This expert opinion article demonstrates that CTEPH remains an underdiagnosed and underappreciated condition. There are patients missing out on potentially curative surgery because of variability in operative assessment.

The authors seek to emphasize the importance of seeking an expert second opinion and introduce the possibility of remote assessment by expert high-volume surgeons during the evaluation process. CHEST-1 evaluated riociguat for the treatment of inoperable chronic thromboembolic $\mathrm{PH}$

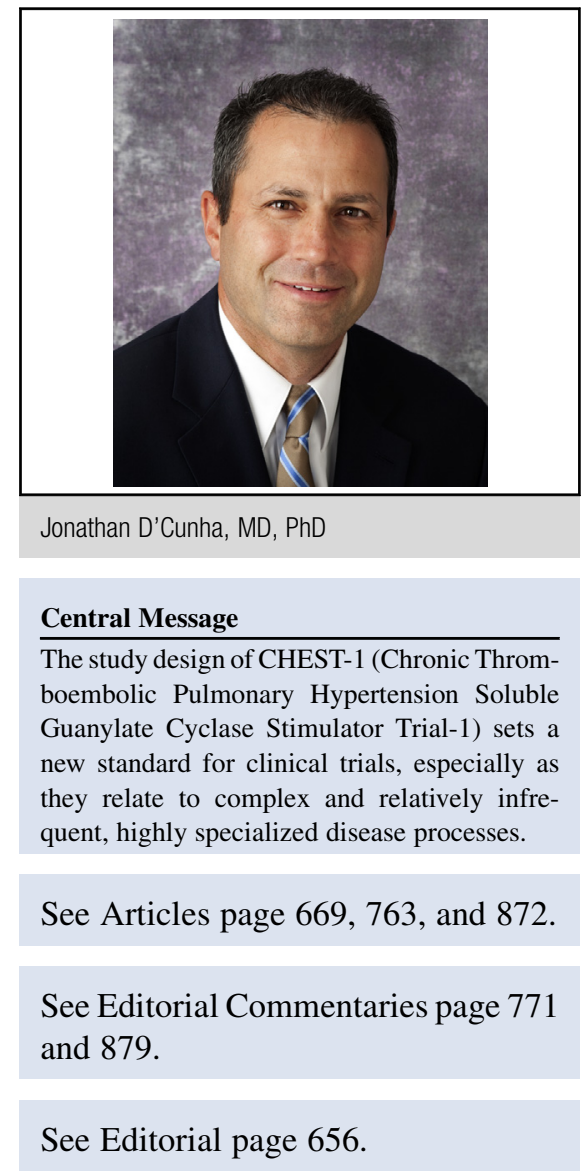

or persistent/recurrent $\mathrm{PH}$ after PEA. It was a phase III pivotal trial that demonstrated significant efficacy for pharmacotherapy in CTEPH. Screened patients underwent independent adjudication by a committee of experienced surgeons or local adjudication in collaboration with an experienced surgeon. Following the methodology in this study, 69 of 312 patients had their "inoperable" label reversed. This process of misclassifying patients has the potential to deny patient of receiving curative surgery. An uncommon disease with a potentially significant morbidity deserves quality standards as described in this trial.

The operability assessment in CTEPH is a complex and subjective process that is based on experience, like so 
many of our problems in cardiothoracic surgery. This study sets the standards for evaluation, which should include operability assessment by an experienced PEA team. CHEST-1 included a rigorous prospective assessment of operability by expert PEA surgeons that essentially solidified the fact that only technically inoperable patients or those with persistent/recurrent $\mathrm{PH}$ after PEA were enrolled. This is the type of rigor that has led to the pivotal findings regarding the efficacy of riociguat in CTEPH. Further, this methodology also demonstrates the potential power of remote expert opinion. The demonstrated success of this unique approach has implications not only for future CTEPH work, but other clinical trials.

The study design of CHEST-1 sets new standard for clinical trials especially as they relate to complex and relatively infrequent, highly specialized disease processes that benefit from multidisciplinary input/discussion. The process should be analyzed carefully, and its thought- provoking design should stimulate improved trial design through similar methodologies where feasible.

\section{References}

1. Humbert M. Pulmonary arterial hypertension and chronic thromboembolic pulmonary hypertension: pathophysiology. Eur Respir Rev. 2010;19:59-63.

2. Lang IM, Klepetko W. Chronic thromboembolic pulmonary hypertension: an updated review. Curr Opin Cardiol. 2008;23:555-9.

3. Moser KM, Bloor CM. Pulmonary vascular lesions occurring in patients with chronic major vessel thromboembolic pulmonary hypertension. Chest. 1993;103:685-92.

4. Peacock A, Simonneau G, Rubin L. Controversies, uncertainties and future research on the treatment of chronic thromboembolic pulmonary hypertension. Proc Am Thorac Soc. 2006;3:608-14.

5. Simonneau G, Robbins IM, Beghetti M, Channick RN, Delcroix M, Denton CP, et al. Updated clinical classification of pulmonary hypertension. J Am Coll Cardiol. 2009;54(1 suppl):S43-54.

6. Jenkins D, Mayer E, Screaton N, Madani M. State-of-the-art chronic thromboembolic pulmonary hypertension diagnosis and management. Eur Respir Rev. 2012;21:32-9.

7. Jenkins DP, Biederman A, D’Armini AM, Dartevelle P, Gan H, Klepetko W, et al. Operability assessment in CTEPH: lessons from the CHEST-1 study. J Thorac Cardiovasc Surg. 2016;152:669-74. 